\title{
AS CAPAS DE CORDEL EM XILOGRAVURA NA TIPOGRAFIA SÃO FRANCISCO (1932-1982)
}

\author{
Paulo Jeyson Barros Paiva \\ Universidade Federal de Pelotas \\ paulopaivadg@gmail.com
}

\begin{abstract}
Resumo: Os folhetos de cordel tiveram uma vasta distribuição nas regiões norte e nordeste do Brasil durante a primeira metade do século XX. A Tipografia São Francisco foi uma das maiores editoras de cordel do país, funcionando entre os anos de 1932 e 1982 na cidade de Juazeiro do Norte, Ceará. Fundada por José Bernardo da Silva, essa editora foi responsável pela popularização da xilogravura nas capas de folhetos de cordel. Através de pesquisa documental no acervo digital da Fundação Casa de Rui Barbosa, este estudo tem como objetivo resgatar a produção dessas capas e os principais xilógrafos que trabalharam para a Tipografia.
\end{abstract}

Palavras-chave: Folhetos de cordel, Design editorial, História do Design, Xilogravura.

\begin{abstract}
The folhetos de cordel had a large distribution in brazilian north and northeast during the first half of the twentieth century. The Tipografia São Francisco was one of the largest cordel publishers in the country, working between the years 1932 and 1982 in in the town of Juazeiro do Norte, Ceará. Founded by José Bernardo da Silva, this publisher was responsable for popularization of woodcuts on the covers of folhetos de cordel. Through documental research in the Fundação Casa de Rui Barbosa's digital collection, this study aims to rescue the prodution of this covers and the mains xilographers that worked for the Tipography.
\end{abstract}

Keywords: Folhetos de cordel, Editorial design, Design's History, Woodcut.

\section{INTRODUÇÃO}

É de nosso conhecimento que, no Brasil, eram exercidas atividades que podemos classificar como "design" antes da instauração do primeiro curso superior em 1963. De acordo com Rafael Cardoso:

Durante os cinquenta a cem anos anteriores a tal data eram exercidas entre nós atividades projetuais com alto grau de complexidade conceitual, sofisticação tecnológica e enorme valor econômico, aplicadas à fabricação, à distribuição e ao consumo de produtos industriais (CARDOSO, 2005, p.8). 
Podemos citar, por exemplo, os rótulos de bebidas alcóolicas, as embalagens de cigarro, o projeto gráfico de revistas como a Maçã, O Malho e Para. Na região Nordeste brasileira, foram os chamados folhetos de cordel que se destacaram durante esse período. Produzidos em papel barato, compostos geralmente de 16 ou 32 páginas, medindo $11 \times 16 \mathrm{~cm}$ e com capas ilustradas geralmente em zincografia ou xilogravura, esses folhetos tiveram uma vasta distribuição, durante a primeira metade do século XX, por todo o território nordestino e parte da região norte.

Este artigo visa resgatar a produção de capas de folhetos de cordel produzidas em xilogravura na Tipografia São Francisco, uma das maiores editoras de cordel do país e responsável pela popularização desse tipo de capa. Os folhetos pesquisados compõem o acervo digital da Fundação Casa de Rui Barbosa (FCRB) ${ }^{1}$.

\section{OS FOLHETOS DE CORDEL E A TIPOGRAFIA SÃO FRANCISCO}

A produção de folhetos de cordel no Brasil começou em meados do século XIX, através do poeta paraibano Leandro Gomes de Barros. Durante esse período, a indústria gráfica nacional vinha passando por grandes transformações como o barateamento do papel, a mecanização das prensas tipográficas, a introdução da litografia $^{2}$ e da zincografia ${ }^{3}$ como técnicas de impressão de imagens e o advento da fotografia. (CARDOSO, 2005)

Os primeiros folhetos de cordel tinham capas que se assemelhavam visualmente as capas de livros publicadas no século XIX, pois a concepção gráfica era baseada em recursos tipográficos: tipos, fios, vinhetas e molduras. A popularização de capas ilustradas aconteceu com o editor paraibano João Martins de Athayde entre as décadas de 1910 e 1920. De acordo com Rosilene Alves de Melo:

João Martins de Athayde foi um dos responsáveis pela introdução de imagens nas capas dos folhetos, quando passou a recorrer a desenhistas e caricaturistas que trabalhavam para o Jornal do Recife e para o Diário da Manhã para produzirem as ilustrações (MELO, 2010, p.107).

Os folhetos editados por Athayde estampavam desenhos produzidos em litogravura e zincogravura. Sua editora foi uma das maiores de sua época e teve funcionamento entre os anos de 1909 a 1950, época em que vendeu os seus direitos de publicação a José Bernardo da Silva, dono da Tipografia São Francisco.

Outro tipo de capa comum na época eram as fotos de artistas de cinema, que eram transferidas para o clichê de metal através da autotipia. De acordo com Joaquim Marçal Andrade, nessa técnica:

A imagem original de tons contínuos era reproduzida através de uma malha (ou retícula) de vidro, sendo então fragmentada em pequenos pontos,

\footnotetext{
${ }^{1}$ Situada no Rio de Janeiro, a Fundação Casa de Rui Barbosa tem uma das maiores coleções de folhetos de cordéis do país, com cerca de 9.000 exemplares. O acervo de cordéis pode ser acessado através do seguinte endereço: http://docvirt.com/docreader.net/docreader.aspx?bib=CordelFCRB

${ }^{2}$ Técnica de gravura baseada na repulsão da água pela gordura, sua matriz é a pedra calcária e o desenho é feito na pedra através de lápis gorduroso, litográfico ou tinta especial aplicada à um pincel.

${ }^{3}$ Semelhante a litografia, a zincografia tem como matriz uma chapa de metal e o desenho pode ser gravado com uma incisão direta (riscar, gravar) ou a partir de imersão em ácido.
} 
distribuídos de maneira regular e cujo tamanho variava em função da tonalidade específica de cada área da imagem. Através desse processo, gravava-se uma chapa denominada clichê, onde os pontos, em alto-relevo, correspondiam às áreas escuras da imagem. Os clichês podiam ser montados juntamente com os blocos de texto e impressos simultaneamente pelo processo tipográfico então adotado na indústria gráfica (CARDOSO, 2005, p.81).

Apesar de o primeiro registro de xilogravura em folheto de cordel ser datado de 1907, quando apareceu na página interna do folheto A Vida de Antonio Silvino (FRANKLIN, 2007), essa técnica só veio conquistar seu espaço definitivo nas capas de cordel com a Tipografia São Francisco, onde surgiu como alternativa de baixo custo e rápida distribuição, pois as matrizes de metal vinham de Recife ou Fortaleza (distantes cerca de 500 km), já que em Juazeiro não havia uma casa de fundição para produzir os clichês.

José Bernardo da Silva, dono da Tipografia São Francisco, passou a encomendar xilogravuras a artistas da região. Elas eram produzidas principalmente a partir da madeira imburana, cortados com gilete, estilete ou ponta de faca e não possuíam nenhuma influência da gravura medieval europeia do século XIV (MARANHÃO, 1981, p.71).

Diferentemente da popularidade que tem hoje em dia entre o grande público, a xilogravura, nessa época, não era popular entre os consumidores de folhetos de cordel, que preferiam as capas em clichê de metal que estampavam fotos de artistas de cinema conhecidos e apresentavam uma qualidade gráfica melhor que as matrizes de madeira. A xilogravura acabou conquistando seu espaço com o tempo, pois agradou principalmente os pesquisadores do cordel, já que essa técnica expressa bem a cultura da região nordeste através de seus desenhos entalhados na madeira.

Cabe acrescentar que a importância dos cordéis vai além da literatura e do folclore. Segundo Ribamar Lopes:

Foi o primeiro jornal do nosso sertanejo, antes do aparecimento, nas zonas rurais, do jornal propriamente dito, do rádio, da TV. Levado pelos vendedores ambulantes às nossas feiras do interior e mercados, ele difundia notícias sobre grandes acontecimentos de repercussão internacional, nacional, estadual e local (LOPES, 1994, p.8).

Para se ter uma ideia, o cordel do poeta Monteiro Silva sobre o suicídio de Getúlio Vargas chegou a vender 70 mil exemplares em 48 horas. Essa popularidade do cordel se deveu muito também ao baixo custo de produção e a rapidez com que era produzido, trazendo sempre fatos do cotidiano da população. Abaixo, segue um comparativo entre os preços de um folheto de cordel e outros tipos de publicações populares na época: 
Quadro 1 - Comparativo de preços

\begin{tabular}{|l|l|l|}
\hline Publicação & Ano & Preço (Cr\$) \\
\hline Jornal do Brasil & 1952 & 1.00 \\
\hline Revista Manchete & 1952 & 5.00 \\
\hline Revista O Malho & 1952 & 10.00 \\
\hline Romance da Filha do Pescador (Cordel) & 1952 & 3.00 \\
\hline Quadrinho do Batman & 1953 & 3.00 \\
\hline
\end{tabular}

Fonte: Elaborado pelo autor, com base na pesquisa realizada

\section{OS ILUSTRADORES DE CAPAS}

Inúmeros foram os xilógrafos que produziram capas para a Tipografia São Francisco, entre eles, merecem destaque: Mestre Noza, João Pereira da Silva, Antônio Batista da Silva, Manoel Santeiro, Damásio Paulo, Walderêdo Gonçalves e Stênio Diniz. A seguir, serão apresentadas capas de cordel talhadas por Damásio Paulo, Waldêredo Gonçalves e Stênio Diniz, será também apresentado um caso de redesenho de uma capa em clichê de metal para xilogravura.

\subsection{Damásio Paulo}

Damásio Paulo da Silva era poeta e foi contratado por José Bernardo da Silva para ser gerente da Tipografia São Francisco, além de cuidar da composição dos clichês e da impressão de folhetos, Damásio passou também a fazer xilogravuras para as capas de cordel.

De acordo com Rosilene Melo "A passagem do poeta Damásio Paulo da Silva" pela Tipografia São Francisco é envolta em mistérios" (MELO, 2010, 82), pois não se sabe muito sobre o poeta e xilógrafo, que era conhecido pelo mau humor, Damásio trabalhou na Tipografia de José Bernardo entre os anos de 1938 e 1949, "quando ao final de um dia de trabalho afirmou categoricamente: 'amanhã não venho mais nunca, minha alma não terá vergonha se ainda pisar numa tipografia'." (MELO, 2010, 82), desde então, as notícias sobre Damásio foram escassas. A seguir, segue um folheto ilustrado por ele publicado pela Tipografia São Francisco: 


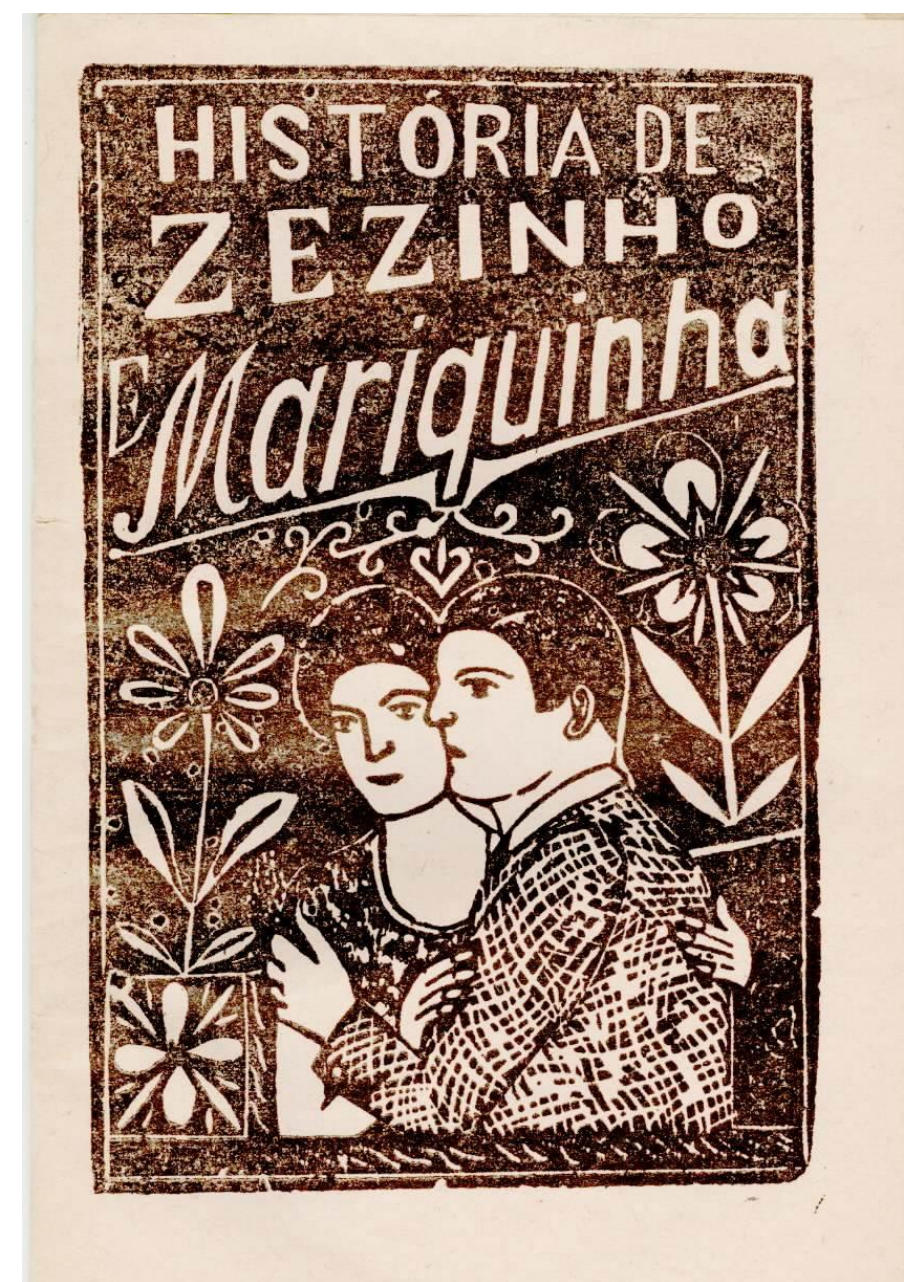

Figura 1 - Folheto ilustrado por Damásio Paulo

Fonte: Acervo FCRB

Nesse folheto é possível observar, primeiramente, em destaque, o título da história na parte de cima e um casal logo abaixo. Essa capa se diferencia do padrão estrutural das capas de cordel da época, onde o nome do autor, do editor e o título, vinham no topo do folheto e não interagiam com a ilustração (no folheto ilustrado por Walderêdo, apresentado adiante, pode ser observada tal estrutura).

Observa-se também que todo o texto estar em caixa alta, exceto pelo nome "Mariquinha" que possui apenas o " $\mathrm{M}$ " em maiúsculo e também se destaca por manuscrita. Quanto ao desenho, observa-se que Damásio se preocupou em preencher a composição, utilizando uma vinheta abaixo do nome "Mariquinha" e desenhos de plantas em torno do casal. Vale destacar a preocupação do xilógrafo com a textura na blusa do homem, o que denota um trabalho minucioso do artista.

Algo comum entre as xilogravuras para cordel é o rosto dos personagens que lembram muito os alto-relevo e representações pictóricas do antigo Egito, onde os rostos possuíam traços simples e não apresentavam perspectiva.

Apesar de não haver a assinatura de Damásio Paulo na capa do folheto, ela foi atribuída ao artista através do Museu de Artes da Universidade Federal do Ceará (MAUC), que enviou emissário à Juazeiro do Norte em 1962 para adquirirem matrizes e encomendar álbuns aos xilógrafos locais, com o intuito de compor o acervo do então recém-criado museu. 
Por último, cabe aqui fazer duas observações: 1) Por causa do seu método de impressão, é possível perceber que todos os folhetos de cordel impressos em clichê de metal ou de madeira, possuem uma margem de segurança, fato esse, que impossibilita o uso de imagens sangradas. 2) A vasta maioria das editoras de cordel, até meados do século $\mathrm{XX}$, imprimiam seus folhetos apenas com uma cor, devido ao custo que seria fazer uma matriz para cada cor, em razão disso, os editores imprimiam a capa dos folhetos com papel manilha de diferentes cores para simular, ao menos, o uso de preto mais uma cor (no caso, do papel).

\subsection{Walderêdo Gonçalves}

Walderêdo Gonçalves nasceu na cidade do Crato/CE em 19 de abril de 1920. Sua primeira xilogravura foi feita ainda aos 15 anos de idade, quando trabalhava como de tipógrafo na livraria e tipografia de Pergentino Maia e recebeu a encomenda de uma ilustração para um folheto de orações, de acordo com o próprio artista:

\footnotetext{
Como não tinha nada pra ilustrar a capa, me perguntaram, meio incrédulos, se eu não podia fazer uma xilogravura. Fui para casa almoçar, fiz um taco de madeira, talhei e deu certo. De tarde, quando voltei, a xilogravura do Coração de Jesus estava pronta. (TEMÓTEO, 2002, p.61).
}

Daí em diante, Walderêdo passou a produzir xilogravuras sob encomenda para José Bernardo da Silva e outras tipografias da região. Além das capas de cordel, o artista desenhou rótulos de bebidas, cigarros e até capas de livros. Suas xilogravuras foram expostas em vários museus e galerias do mundo.

Em entrevista para o pesquisador Jurandy Temóteo, o xilógrafo relata que para criar suas xilogravuras, ele lia as histórias, idealizava os desenhos e só depois entalhava na madeira (TEMÓTEO, 2002). A seguir, segue a capa do folheto A chegada de Lampião no céu ilustrada por Walderêdo: 


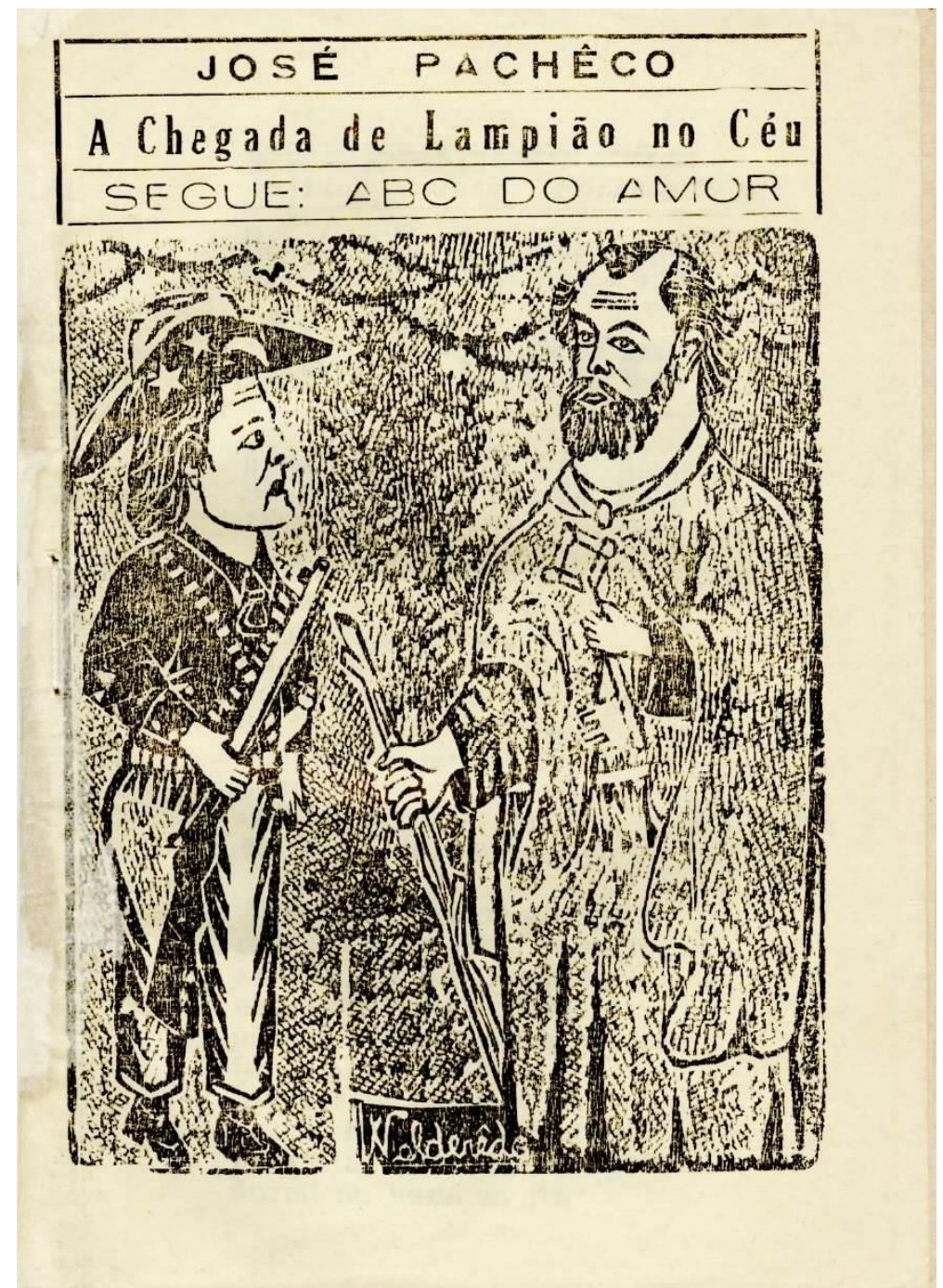

Figura 2 - Folheto ilustrado por Walderêdo Gonçalves

Fonte: Acervo FCRB

Na xilogravura de Walderêdo, observa-se o padrão estrutural utilizado pela maioria das capas de cordel, onde o nome do autor e o título da história estão em um bloco separado ao da ilustração. Quanto à xilogravura, temos Lampião postado à esquerda, vestido com seus trajes de cangaceiro e portando uma espingarda; à sua direita, estar São Pedro com um cajado na mão direita, e a chave do céu na mão esquerda.

Constata-se que Walderêdo foi além do caso anteriormente exposto, de Damásio Paulo, ao preencher todo o plano de fundo do desenho com uma textura, tornando a composição muito densa e confusa, dificultando, por exemplo, a nitidez das silhuetas das nuvens próximas às cabeças de Lampião e São Pedro e a própria assinatura do artista na parte inferior do folheto.

\subsection{Stênio Diniz}

José Stênio Silva Diniz nasceu em Juazeiro do Norte no ano de 1953, neto de José Bernardo da Silva, Stênio acompanhou desde cedo o ambiente da Tipografia São Francisco. Ainda quando criança trabalhou juntando papel durante o dia e fazendo o acabamento dos folhetos (encadernagem, dobragem e encapagem) durante a noite. 
Stênio Diniz começou a desenhar capas de cordel, aos 15 anos de idade, inspirado nas xilogravuras de Mestre Noza e Walderêdo Gonçalves. Sobre o seu início na xilogravura, o artista relata ao pesquisador Gilmar de Carvalho:

\begin{abstract}
Inclusive foi o Noza quem me deu a segunda madeira pra eu trabalhar, que a primeira eu tive que roubar da gráfica porque falaram "Não, você não sabe fazer, vai estragar essa madeira" (...) Já imprimi e mostrei que eu tava com vontade e que fiz. Ah, bom, ai meu avô viu, já pediu que eu fosse no Noza arranjar madeira lá pra trabalhar. Noza arranjou e eu comecei a fazer. Até hoje. (CARVALHO, 2010, p. 179).
\end{abstract}

Stênio redesenhou muitas capas que eram originalmente em zincografia, para xilogravura, como: Donzela Teodora, Chegada de Lampião no inferno e Peleja de Riachão com o Diabo. A seguir, segue a capa do folheto $A$ chegada de Lampião no inferno publicado pela Tipografia São Francisco:

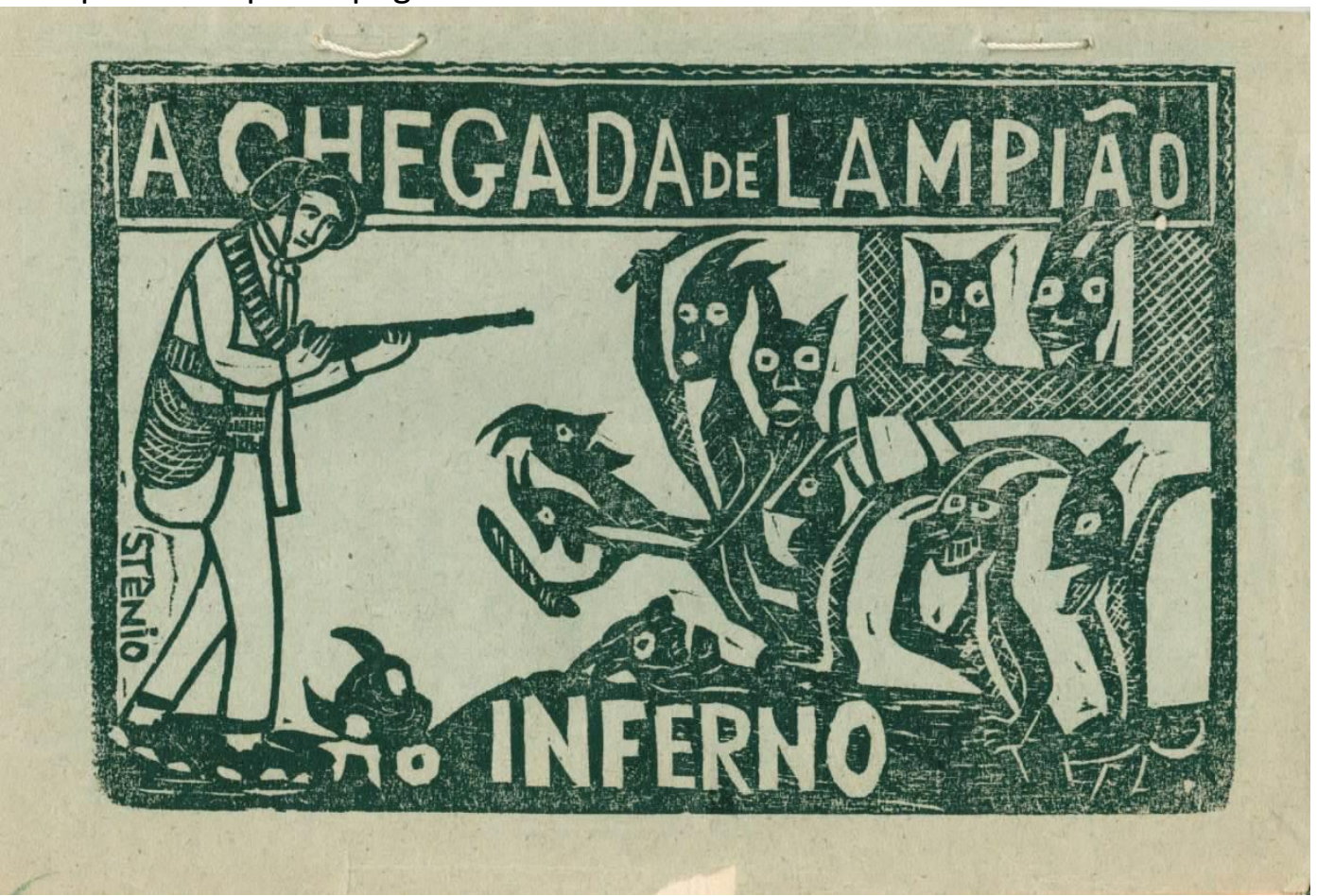

Figura 3 - Folheto ilustrado por Stênio Diniz

Fonte: Acervo FCRB

A capa desenhada por Stênio Diniz se destaca das demais, primeiramente pela disposição do desenho, que esta no formato paisagem (disposição horizontal do papel), disposição que não era comum nos folhetos de cordel. Sobre o título, podemos ver que o artista optou por destacá-lo ao usar as letras em caixa alta e contrastá-las com o fundo escuro, observa-se também que as palavras "no inferno" foram deslocadas para a parte inferior da composição e a palavra "inferno" recebeu um peso maior nas letras.

Sobre a ilustração, Lampião esta a esquerda da capa, apontando sua arma às criaturas que compõe o exército do diabo, alguns estão armados com objetos cortantes, espécies de faca ou foice. Detalhe para uma cabeça de boi no chão próxima a Lampião e as duas criaturas, Lucífer e Satanás, observando a batalha. 
Diferentemente de Damásio e Walderêdo nos exemplos anteriores, Stênio Diniz opta por uma composição limpa, sem texturas ou muitos elementos, opção essa que dá maior clareza a capa e facilita a sua interpretação.

\section{4. $O$ redesenho de capas}

$O$ redesenho de capas de folhetos de cordel era atividade comum entre as editoras de cordel, pois, devido ao exaustivo uso dos clichês na impressão, eles acabavam se desgastando com o passar do tempo.

Essa técnica de redesenho de uma imagem para xilogravura era comum nos periódicos europeus da década de 1840 que estampavam suas fotografias através da xilogravura, os artistas copiavam minunciosamente a foto para a madeira e depois gravam. (CARDOSO, 2005).

A Tipografia São Francisco, por conta da impossibilidade de reprodução de clichês em metal, era palco de tais redesenhos em xilogravura. No acervo da Fundação Casa de Rui Barbosa há inúmeros folhetos redesenhados por Stênio Diniz, a seguir segue o exemplo de redesenho do folheto História de Juvenal e O Dragão:

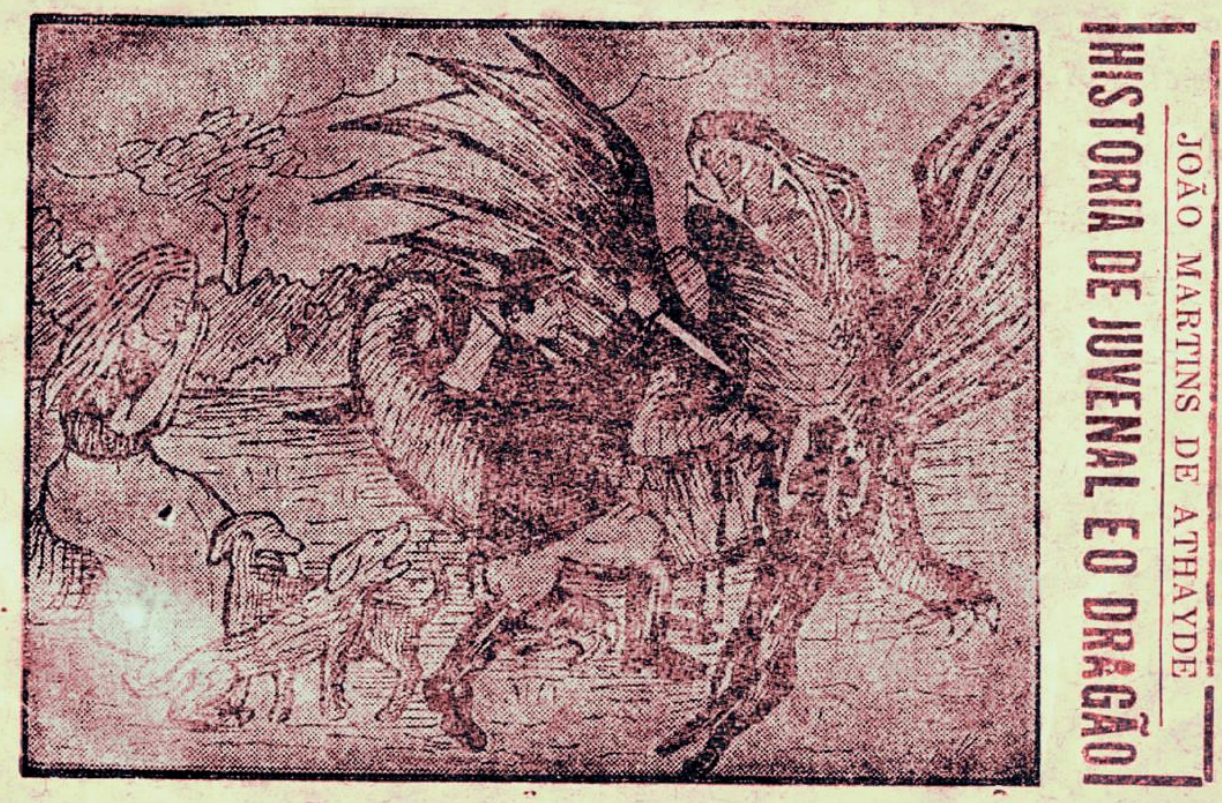

Figura 4 - Folheto ilustrado em zincografia

Fonte: Acervo FCRB 


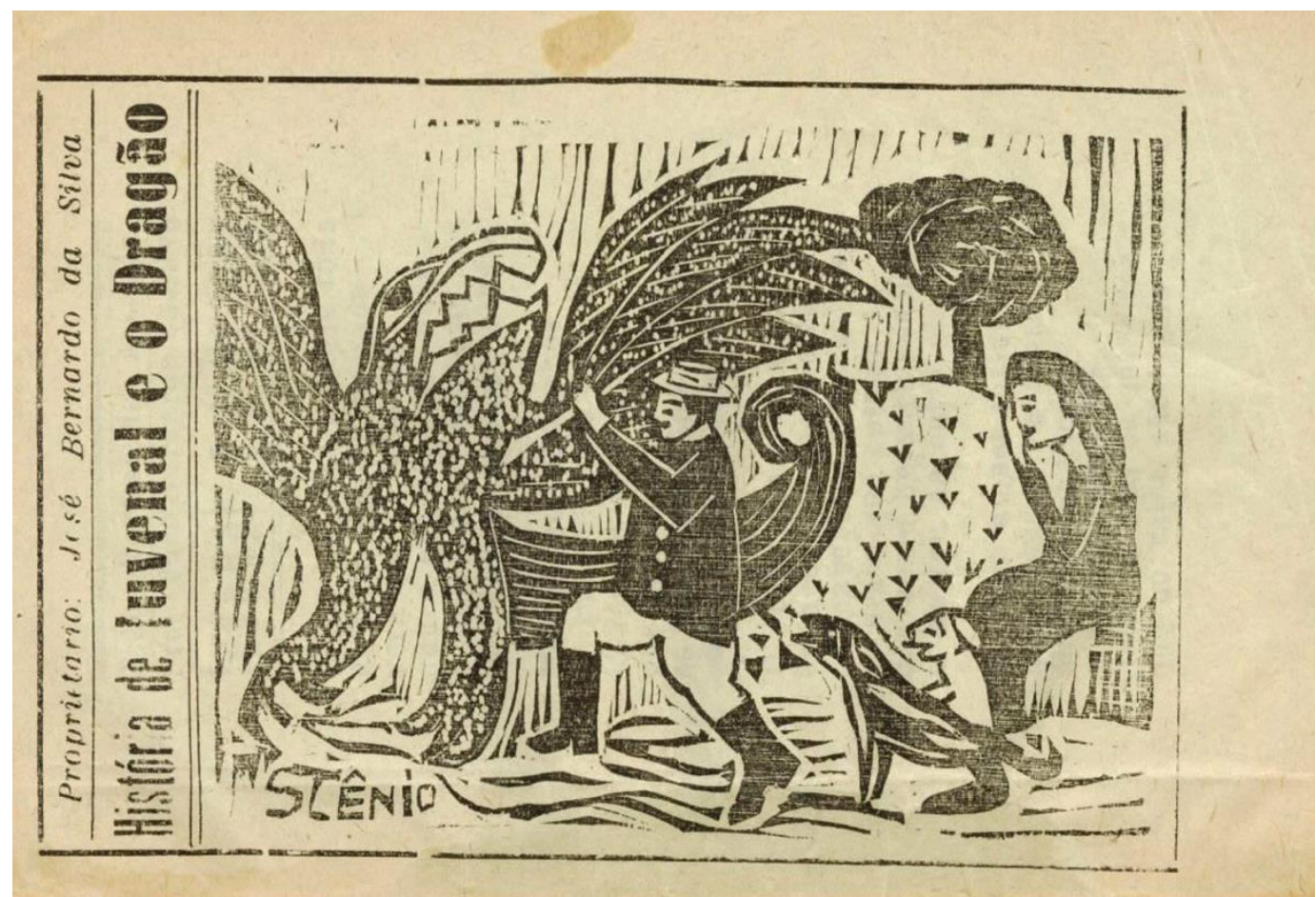

Figura 5 - Folheto redesenhado em xilogravura

Fonte: Acervo FCRB

Na primeira capa, ilustrada em zincografia, observa-se uma figura masculina, representando Juvenal, atacando o dragão com uma adaga. À esquerda deles, está a princesa, supostamente aflita, pois está de olhos fechados, cabeça baixa e com a mão cobrindo o rosto. Logo abaixo, ainda é possível perceber dois cachorros, há também um terceiro cachorro, saltando em direção à asa esquerda do dragão, porém a qualidade da imagem dificulta uma melhor visualização dele.

Na capa redesenhada por Stênio Diniz, logo se percebe que o artista procurou manter os mesmos elementos da capa original, porém, aplicando uma identidade própria. A disposição dos personagens foi invertida e o artista procurou dar um maior destaque a eles, utilizando poucos elementos compositivos. Cabe acrescentar que na composição de Stênio, foram retratados apenas dois cachorros e não três, como na história do folheto.

\section{CONCLUSÃO}

Os estudos acerca da produção de folhetos de cordel no nordeste brasileiro abrem espaço para inúmeras pesquisas futuras. De acordo com Rafael Cardoso:

\footnotetext{
Se existiram atividades projetuais em larga escala no Brasil entre 1870 e 1960, e se estas não tiveram como base uma linha única de pensamento, uma determinada doutrina ou estética, então a produção que delas resultou é representativa de uma tradição rica, variada e autenticamente brasileira, que terá assimilado e conciliado uma série de influências dispares (CARDOSO, 2005, p.11).
}

Isso confirma a importância desses estudos de resgate da memória gráfica nacional. Nessa pesquisa apresentada, o enfoque foi a produção de capas de cordel em xilogravura na Tipografia São Francisco, ao final dos estudos, foi possível perceber 
o grande número de artistas que produziram capas para a Tipografia, além de sua rica e vasta produção.

A produção desses xilógrafos abre perspectiva para estudos relacionados ao design vernacular, ou seja, aquilo que foi feito à margem do conhecimento erudito, já que a grande maioria não teve nenhum estudo relacionado às artes gráficas e aprenderam a arte de gravar e desenhar capas através de conhecimento empírico.

Vale acrescentar que o avanço da indústria gráfica nacional a partir da metade do século $X X$, a popularização da impressão offset e o consequente barateamento do preço final dos impressos, fez com que as capas em xilogravura fossem perdendo espaço nos folhetos de cordel. Hoje em dia, já não é mais comum ver xilogravuras nas capas dos folhetos, quando aparecem, são na verdade reproduções de xilogravuras previamente digitalizadas, impressas agora em offset. Por outro lado, a xilogravura de Juazeiro do Norte não ficou atrelada apenas a literatura de cordel, após chegar ao conhecimento dos eruditos e estudiosos da época, ela passou a ganhar reconhecimento, se tornando objeto de arte e compondo o acervo de museus e galerias. A cidade continua revelando artistas que produzem suas gravuras para as mais diversas aplicações.

Por último, cabe ressaltar que com os possíveis desdobramentos dessa pesquisa, o objetivo agora será iniciar um novo estudo sobre o começo da produção de capas de cordel no Brasil, ou seja, as capas tipográficas e as produzidas em zincografia e litografia, pois se entende que um estudo mais completo sobre essa produção de capas poderá contribuir para futuros estudos acerca de uma identidade do design nordestino. 


\section{REFERÊNCIAS}

CAMARGO, Mário de (org.). Gráfica: Arte e indústria no Brasil: 180 anos de História. 2 edição. São Paulo: Bandeirantes Gráfica, 2003.

CARDOSO, Rafael (org.). Impresso no Brasil, 1808-1930: destaques da história gráfica do acervo da Biblioteca Nacional. Rio de Janeiro: Verso Brasil, 2009. . O Design brasileiro antes do Design: Aspectos da história gráfica, 1870-1960. São Paulo: Cosac Naify, 2005.

CARVALHO, Gilmar. Desenho gráfico popular. Instituto de Estudos Brasileiros/USP, 2000.

Madeira Matriz: Cultura e memória. São Paulo: Annablume, 1998. Memórias da xilogravura. Fortaleza: Expressão Gráfica, 2010. Xilogravura: Doze escritos na madeira. 2. ed. Fortaleza: Museu do

Ceará, 2011.

Xilogravura: Os percursos da criação popular, in: Revista do Instituto de Estudos Brasileiros, São Paulo, no 39, 1995.

DONES,V.L.. As apropriações do vernacular pela comunicação gráfica. In: Congresso Brasileiro de Ciências da Comunicação, 27., 2004. Porto Alegre. Anais... São Paulo: Intercom, 2004.

FRANKLIN, Jeová. Xilogravura popular na Literatura de Cordel. Brasília: LGE, 2007. LOPES, Ribamar. Literatura de Cordel: Antologia. 3a edição. Fortaleza: Banco do Nordeste do Brasil, 1982.

MARANHÃO, Liêdo. O folheto popular: Sua capa e seus ilustradores. Recife: Fundação Joaquim Nabuco - Editora Massangana, 1981.

MELO, Chico Homem de; RAMOS, Elaine. Linha do tempo do design gráfico no Brasil. São Paulo: Cosac Naify, 2011.

MELO, Rosilene Alves de. Arcanos do Verso: Trajetórias da literatura de cordel. Fortaleza: 7 Letras, 2010.

NIEMEYER, Lucy. Design no Brasil: Origens e instalação. 4 edição. Rio de Janeiro: 2AB, 2007.

PAIVA, Paulo. Memórias do cordel: O legado da Tipografia São Francisco para o design brasileiro. Pelotas, 2011. 102 f. Trabalho de Conclusão de Curso (Graduação em Design Gráfico) - Centro de Artes da Universidade Federal de Pelotas.

SOBREIRA, Jeová. Xilógrafos de Juazeiro. Brasília: Fundação Astrojildo Pereira, 2007. TEMÓTEO, Jurandy. A xilogravura de Walderêdo Gonçalves no contexto da cultura popular do Cariri. João Pessoa: A Província, 2002.

\section{Folhetos Consultados}

BARROS, Leandro Gomes de. História de Juvenal e o dragão. Juazeiro do Norte:

Tipografia São Francisco, 1949.

Tipografia São Francisco, s/d.

. História de Juvenal e o dragão. Juazeiro do Norte:

LIMA, Silvino Pirauá de. Historia de Zezinho e Mariquinha. Juazeiro do Norte:

Tipografia São Francisco, s/d.

PACHECO, José. Chegada de Lampião no céu. Juazeiro do Norte: Tipografia São Francisco, 1973.

. A chegada de Lampião no Inferno / Triste sorte de uma meretriz.

Juazeiro do Norte: Tipografia São Francisco, 1977. 